\title{
Municipal Service Quality and Citizen Satisfaction in Southern Thailand
}

\author{
Safiek Mokhlis (Corresponding author) \\ Faculty of Management and Economics, Universiti Malaysia Terengganu \\ 21030 Kuala Terengganu, Malaysia \\ Tel: +0609-6684823Ｅ-mail: safiek@umt.edu.my \\ Yaleakho Aleesa \\ Faculty of Humanities and Social Science, Yala Rajabhat University \\ 133 Tessaban 3 Road, Tambon Sateng, Muang District, \\ Yala Province 95000 Thailand \\ Ibrahim Mamat \\ Center of Socio-Economic Development \\ Universiti Malaysia Terengganu \\ 21030 Kuala Terengganu, Malaysia
}

Received: June 12, 2011 Accepted: June 20, $2011 \quad$ DOI: 10.5296/jpag.v1i1.717

\begin{abstract}
The objectives of the research are two-folds: (1) to examine the quality of municipal services provided by local government in southern Thailand; and (2) to identify the most important service quality dimensions that determine citizen satisfaction. The questionnaires were distributed to 234 respondents in Tambon Khok Pho, a subdistrict of Khok Pho in Pattani Province of southern Thailand. Descriptive statistics, exploratory factor analysis, Pearson correlation and stepwise multiple regression were conducted to analyze the data. Results indicate that (1) the five dimensions of SERVQUAL represent a valid instrument to measure municipal service quality in Thai setting; and (2) four service quality dimensions, namely tangibility, empathy, assurance and responsiveness significantly predicted citizen satisfaction,
\end{abstract}


with an adjusted $R^{2}$ of 0.5 . The findings can be used as a guide for municipal officials to improve the crucial quality attributes and enhance citizen satisfaction.

Keywords: Service quality, SERVQUAL, satisfaction, local government, Thailand

\section{Introduction}

One of the most significant challenges facing services organizations today is to provide consistently high quality services. The delivery of consistent service quality is arguably the most vital factors that contribute to the establishment of credibility and reputation of the organizations in the eyes of the public. It is well recognized that providing high quality services has a beneficial effect on the bottom-line performance for the organization. Indeed, there is a growing body of empirical evidence indicating that providing top quality services enhances profitability, improves productivity, spreading positive word-of-mouth, increases market share and return on investment, and reduces costs (Sachdev \& Verma, 2004).

Like many other services organizations, public services organizations specifically those ones operating at local government level, are not immune to the pressures to improve the quality of their services on a continuous basis. Municipal authorities for example, faces more daunting tasks than those in the private sector in their efforts to provide excellent service and maintain citizen satisfaction. A wide variety of influences are effectively bringing about awareness of quality issues, and of concepts such as quality management. Some of these influences arise directly from local authorities' genuine desire to enhance their public image by improving the quality of those services provided to the community, while others come "imposed" or "forced" either by means of public initiatives or through an increase in consumers' awareness of their rights (Vázquez, Gutiérrez \& García, 2005).

Quality is a pivotal factor for the transformation of municipal services and a critical driving force for better citizen satisfaction (Rodríguez, Burguete, Vaughan \& Edwards, 2009). Efficient and effective delivery system becomes the main focus of the government of many countries due to insistence and hopes from society for local authorities giving their services up to the quality standard as expected by the tax payers (Wan Yusof, Ismail \& Newell, 2008). However, providing high quality and cost-effective public services is not an easy task. It involves creating organizations with the right approaches, establishing clear ways of how to deliver services and putting the right people in place to respond to the needs of citizens. It also requires a combination of good policy development, successful implementation, a good understanding of citizens' needs and expectations, appropriate resources and technology, a responsive organizational culture and well trained staff (Rodríguez et al. 2009). At the same time, municipalities must balance the revenue they received with the high cost of providing more efficient services demanded by citizen.

Understanding exactly what the citizen expect is the most important step in defining and delivering quality service. Gaining citizen feedback provides valuable insight into how well the municipal authority meet their customers' needs. The information can be used in quality improvement programs to help municipal councilors recognize opportunities to improve services and creation of a positive perception among citizen. Quantitative assessments of 
service quality can also identify gaps between citizens' perceptions of municipal services and that of councilors. Finally, service quality assessments can be used as a strategic tool for marketing municipal services.

This paper represents a preliminary investigation of municipal service quality and its influence on citizen satisfaction. In particular, the study attempted to: (1) examine the existence of latent factors hypothesized to be dimension of service quality in the context of municipal services provided by local government; and (2) identify the most important service quality dimensions that determine citizen satisfaction. Tambon Khok Pho, located in Pattani Province of southern Thailand, was purposively selected as the site of this study.

The remaining part of this paper is structured in the following manner. Section 2 reviews the relevant literature on service quality and customer satisfaction. A description of the methodology adopted in this study is discussed in Section 3. Section 4 presents the results, whilst implications of the findings appear in Section 5.

\section{Literature Review}

\subsection{Service quality}

Service quality is a concept that has attracted considerable interest and debate in the marketing literature because of the difficulties in both defining it and measuring it with no overall consensus emerging on either (Wisniewski, 2001). One that is commonly used defines service quality as the ability of the organization to meet or exceed customer expectations. It is the result of the comparison that customers make between their expectations about a service and their perception of the way the service has been performed (Zeithaml et al. 1990). If expectations are greater than performance, then perceived quality is less than satisfactory and hence customer dissatisfaction occurs (Parasuraman, Zeithaml \& Berry, 1985).

Most of the recent work on service quality in marketing can be credited to the pioneering and continuing work of Parasuraman, Berry and Zeithaml (Fisk, Brown \& Jo, 1993). In a seminal research study, Parasuraman, Zeithaml, and Berry (1985) identified ten dimensions of service quality based upon a series of focus group studies. These dimensions are: (1) tangible features, (2) reliability, (3) responsiveness, (4) communication, (5) credibility, (6) security, (7) competence, (8) courtesy, (9) understanding, and (10) access.

From that initial research, Parasuraman et al. (1988) developed a service quality instrument called SERVQUAL that consisted of 22 pairs of statements which measure customer expectations and perceptions of service delivered on a seven- or nine-point Likert scale. For each pair of statements, the gap difference between the two scores is calculated. The idea is that the service is good if perceptions meet or exceed expectations and problematic if perceptions fall below expectations. The scale combined ten components into five generic dimensions of service quality which they claimed "provides a basic skeleton [. . .] which can be adapted or supplemented to fit the characteristics or specific research needs of a particular organization" (p. 31). These dimensions "capture[s] facets of all ten originally conceptualized dimensions" regardless of service industries (Zeithaml et al., 1990, p. 26). These dimensions are defined as follows: 
1) Tangibles: the appearance of physical facilities, equipment, personnel, and communication materials;

2) Reliability: the ability to perform the promised service dependably and accurately;

3) Responsiveness: the willingness to help customers and provide prompt service;

4) Assurance: the knowledge and courtesy of employees and their ability to inspire trust and confidence; and

5) Empathy: the approachability, ease of access and effort taken to understand customers' needs.

Since its inception, SERVQUAL has been widely used in replication studies in a variety of industrial, commercial and not-for-profit settings, to assess quality of service provision in terms of what customers expect and what they actually receive. To name a few, the scale has been applied to measure service quality in healthcare (Kilbourne, Duffy, Duffy \& Giarchi, 2004), hotels (Ramsaran-Fowdar, 2007), tourism (Nowacki, 2005), public transports (Liong, Mustafa, Mohamed \& Lee, 2007), library (Ahmed \& Shoeb, 2009), banking (Othman \& Ismail, 2008), courier service (Zisis, Garefalakis \& Sariannidis, 2009), higher education (Tan $\&$ Kek, 2004) and police service (Donnelly, Kerr, Rimmer \& Shiu, 2006). A number of research studies have applied SERVQUAL method to examine the quality of municipal services (Scott \& Shieff 1993; Donnelly, Wisniewski, Dalrymple \& Curry, 1995; Wisniewski \& Donnelly, 1996; Gaster, 1996; Donnelly \& Shiu, 1999; Brysland \& Curry, 2001; Wisniewski, 2001; Van Ryzin, 2004; Rodriguez et al. 2009).

Despite its popularity and wide application, SERVQUAL is exposed to numerous criticisms, from both a conceptual and operational perspective (for a review, refer to Buttle, 1996). The most important criticism of SERVQUAL was the usage of gap analysis results (difference between expectations and perception of the received service) in measuring service quality (Cronin \& Taylor, 1994). Comparing the expectation-perception gaps with perception only, called SERVPERF, Cronin and Taylor (1992) concluded that measurement of service quality based only on perception was enough. They proposed that the performance based measurement approach (SERVPERF) is more in conformance with the existing attitude and customer satisfaction literature and is superior to the perception-expectation gap approach. Indeed, after a thorough review of the prior literature and evidence from three new studies they conducted, Brady et al. (2002) authoritatively declared that the "performance-only" measures of service quality are superior to other approaches.

\subsection{Satisfaction}

Customer satisfaction has been recognized as one of the most important elements of contemporary marketing thought, particularly in the case of service sectors (Bejou, Ennew \& Palmer, 1998) and one of the main goals in marketing (Erevelles \& Leavitt, 1992). Because satisfied customers tend to maintain their consumption pattern or consume more of the same product or service, customer satisfaction has become an important indicator of the future behavior (McQuitty, Finn \& Willey, 2000). Due to its centrality, various theories and models 
have been developed in an effort to define the construct and explain satisfaction in different products/services and consumption stages (for a review, see Erevelles \& Leavitt, 1992).

Marketing scholars are divided over the antecedents of service quality and satisfaction (Ting, 2004). Some researchers believe that service quality leads to satisfaction (Parasuraman et al. 1998; Bitner, 1990) while others think otherwise. Empirical studies regarding this issue support the assertion that service quality is the antecedent of satisfaction (e.g. de Ruyter, Bloemer \& Pascal, 1997; Brady \& Robertson, 2001; Sureshchandar, Rajendran \& Kamalanabhan, 2002). Within this causal ordering, satisfaction is described as a "post-consumption evaluation of perceived quality" (Anderson \& Fornell, 1994). It is an emotional state that results from experiencing a service quality encounter and comparing that encounter with what was expected (Oliver, 1980). Rust and Oliver (1994) offer support for this position in their suggestion that quality is "one of the service dimensions factored into the consumers' satisfaction judgment". As consumer perceive a widening gap between expected and desired levels of service, feeling of dissatisfaction will increasingly develop.

The review of the literature so far has provided support for the idea that there is a strong direct link between service quality and satisfaction. In this paper, we analyze the relationship between components of municipal service quality and citizen satisfaction. The study fills the gap in the literature by focusing on a setting previously overlooked by researchers Thailand.

\section{Methodology}

\subsection{Instrument for survey}

The data were collected by using a structured questionnaire, which consists of three parts. Part A was designed to gather information about the respondent's demographic background such as gender, age, educational level, marital status, income and occupation. Part B consists of 22 statements related to measure respondents' perception towards the service quality of municipal council. The SERVQUAL scale that was designed by Parasuraman et al. (1991) was used in entirety in this study. The respondents were asked to rate their level of agreement with each statement using seven-point scale ranging from 1 (Strongly Disagree) to 7 (Strongly Agree). To counterbalance possible order effects, the items with respect to the various factors have been jumbled up and arranged in a random order. Higher scores on this scale indicate higher levels of service quality. Section $\mathrm{C}$ was designed to gather information about respondents' overall satisfaction with services provided by the municipal council. It consists of six statements, adapted from Cronin and Taylor (1992) and were measured with reference to a 7-point rating scale $(1=$ Very Dissatisfied to $7=$ Very Satisfied $)$.

The questionnaire was originally prepared in English but as most Thai people speak Thai, the English version was translated into Thai by one of the authors. Accuracy of this translation was verified during the questionnaire pretesting stage.

A pilot study involving forty respondents from Tambon Thepa was conducted to test the instrument. The purpose is to determine the appropriateness and relevance of the items in the survey as well as the level of difficulty of the language for the respondents to answer the 
questions. Based on the feedback from the respondents on the instrument, several modifications were made to the rubrics of the questions so that they were more understandable.

\subsection{Data collection}

For the purpose of this study, residents of Tambon Khok Pho, a sub-district of Khok Pho in Pattani Province, Southern Thailand, were taken as study sample. The total number of household in Tambon Khok Pho is estimated at 558. According to the guidelines set by Krejcie and Morgan (1970), the required sample size for a population of 550 to 600 is 234 or $41.9 \%$ of the population.

The survey was administered in February 2009 to a sample of 234 households with the help of three field assistants. From each household, only one individual, the head or the representative of the household was interviewed. The purpose of this was to avoid imitation or repetition of responses among the respondents and to obtain different views. Interviews were conducted by means of a structured questionnaire. The respondents were discreetly and politely approached with the purpose of the study being explained to them. The respondents were then asked if they would voluntarily participate in this study. If they were unable to participate due to time constraint, the researcher would approach them again at another time.

\subsection{Analytic procedure}

Data from 234 valid questionnaires were analyzed using SPSS version 16. Descriptive statistical analysis was used to describe respondents' demographic characteristics and to evaluate service quality perceptions of municipal services. An exploratory factor analysis was performed on the 22 items included in the questionnaire in order to determine underlying dimensions of municipal service quality perceptions. Pearson correlation and stepwise regression analysis were performed to identify which service quality dimensions were correlated strongly with citizen satisfaction.

\section{Findings}

\subsection{Characteristics of the respondents}

Table 1 presents the frequency distribution of the respondents' demographic profile. The sample consisted of 234 respondents of which approximately half were males $(53 \%)$ and females (47\%), with the largest age group between 46 and 55 years old (34.6\%). Regarding the level of education, most of the respondents were primary school leavers $(38.5 \%), 30.3 \%$ had completed upper secondary level, 19.2\% had a diploma and 12\% had a graduate degree. The majority of respondents (35\%) reported income between 5,000 and 6,999 Bath per month. Finally, most of the people in the study were businessman (56\%) and farmers $(22.6 \%)$. Several also worked in the public sector $(13.7 \%)$ whereas only $7.3 \%$ were employees in the private sector. 
Table 1. Demographic Profile of the Sample

\begin{tabular}{|c|c|c|c|}
\hline Characteristic & Categories & Frequency & Percent \\
\hline \multirow[t]{2}{*}{ Gender } & Male & 124 & 53 \\
\hline & Female & 110 & 47 \\
\hline \multirow[t]{5}{*}{ Age } & $<25$ & 2 & .9 \\
\hline & $26-35$ & 42 & 17.9 \\
\hline & $36-45$ & 72 & 30.8 \\
\hline & $46-55$ & 81 & 34.6 \\
\hline & $>56$ & 37 & 15.8 \\
\hline \multirow[t]{4}{*}{ Education } & Primary & 90 & 38.5 \\
\hline & Upper secondary & 71 & 30.3 \\
\hline & Diploma & 45 & 19.2 \\
\hline & Degree & 28 & 12 \\
\hline \multirow[t]{4}{*}{ Monthly income } & $<4,999$ Bath & 58 & 24.8 \\
\hline & $5,000-6,999$ Bath & 82 & 35.0 \\
\hline & 7,000 - 8,999 Bath & 60 & 25.6 \\
\hline & $>9,000$ Bath & 34 & 14.5 \\
\hline \multirow[t]{3}{*}{ Marital status } & Single & 4 & 1.7 \\
\hline & Married & 217 & 92.7 \\
\hline & Widow/widower & 13 & 5.6 \\
\hline \multirow[t]{5}{*}{ Occupation } & Student & 1 & .4 \\
\hline & Merchant/businessman & 131 & 56.0 \\
\hline & Farmer & 53 & 22.6 \\
\hline & Government servant & 32 & 13.7 \\
\hline & Private sector worker & 17 & 7.3 \\
\hline
\end{tabular}

\subsection{Dimensionality of service quality}

In line with good practices suggested by Parasuraman et al. (1988); and Fabrigar, MacCallum, Wegner, and Strahan (1999), exploration of the underlying structure of the data was carried out through exploratory factor analysis (EFA). One critical assumption underlying the appropriateness of factor analysis is to ensure that the data matrix has sufficient correlations to justify its application. A first step is visual examination of the correlations, identifying those that are statistically significant. All correlations are above 0.3 , which is considered substantial for factor analysis (Hair, Anderson, Tatham \& Black, 1998). Furthermore, an inspection of the correlation matrix reveals that practically all correlations are significant at $p<0.01$, and this certainly provides an excellent basis for factor analysis.

The next step involves assessing the overall significance of the correlation matrix with Bartlett test of sphericity, which provides the statistical probability that the correlation matrix has significant correlations among at least some of the variables. The results were significant at $p<0.001,\left(\chi^{2}=2589.242\right)$, which further confirmed that the data were suitable for factor analysis. Finally, Kaiser-Meyer-Olkin (KMO) measure of sampling adequacy was computed 
to quantify the degree of intercorrelations among the variables, and the results indicate an index of 0.882. Since a high-KMO value (close to 1.0) is achieved, the dataset is appropriate for factor analysis (Hair et al. 1998). As for the adequacy of the sample size, there is a 10-to-1 ratio of observations to variables in this study. According to Hair et al. (1998), the ratio for adequate sample size should be at least 10:1, which, in this case falls well within the acceptable limits.

In order to obtain more interpretable results solution, Varimax rotation was employed to rotate the solution. This caused the loadings to be distributed among the selected factors making it easier to interpret results (Hair et al. 1998). Varimax factor rotation was applied to the 22 components using the minimum eigenvalue of one as the criterion to control the number of factors extracted. Using this procedure, five factor groups were extracted. Table 2 represents the final pattern matrix results of the factor analysis for the service quality dimensions. The analysis converged in sixteen iterations and resulted in five homogeneous sub-scales with the eigenvalues of $7.42,2.19,2.037,1.722$ and 1.54. Following a close inspection of the item on each factor, the five factors were summarily named as follows: Empathy (5 items), Tangibility (5 items), Assurance (4 items), Reliability (4 items) and Responsiveness (4 items). The five factors, when added together, accounted for 67.77 per cent of the variation in the data generated, which satisfies the percentage of variance criterion for social science research (Hair et al. 1998).

As indicated in Table 2, based on the factor structure, the convergent and discriminant validity of the five factors is good. The five factors extracted from the 22-item SERVQUAL are similar to the original study conducted by Parasuraman et al. (1988). Examining the individual items, only one out of the 22 items loaded incorrectly on the dimensions extracted in the study by Parasuraman et al. (1988). Finally, the Cronbach's alpha values for the five factors ranged from 0.816 to 0.885 , implying high internal consistency reliability (Hair et al. 1998). 
Table 2. Factor analysis of service quality

\begin{tabular}{|c|c|c|c|c|c|}
\hline \multirow[b]{2}{*}{ Scale Items ${ }^{\mathrm{a}}$} & \multicolumn{5}{|c|}{ Factor Loadings } \\
\hline & $\mathrm{F} 1$ & $\mathrm{~F} 2$ & F3 & $\mathrm{F} 4$ & F5 \\
\hline Empathy 2 & .821 & .112 & .133 & .167 & .061 \\
\hline Empathy 4 & .784 & .193 & .172 & .150 & .119 \\
\hline Empathy 5 & .783 & .253 & .062 & .188 & .228 \\
\hline Empathy 3 & 777 & .180 & .055 & .116 & .219 \\
\hline Empathy 1 & .683 & .083 & .342 & 143 & .079 \\
\hline Tangibility 1 & .129 & .809 & .075 & .147 & .175 \\
\hline Tangibility 4 & .107 & 772 & .134 & .110 & .159 \\
\hline Tangibility 3 & .143 & 751 & .105 & .066 & .153 \\
\hline Reliability 1 & .218 & \begin{tabular}{|l|l}
747 \\
\end{tabular} & .132 & .135 & .063 \\
\hline Tangibility 2 & .143 & .714 & .145 & .113 & .194 \\
\hline Assurance 2 & .142 & .111 & .829 & .045 & .005 \\
\hline Assurance 4 & .174 & .129 & .818 & .052 & .202 \\
\hline Assurance 3 & .135 & .077 & .813 & .058 & .006 \\
\hline Assurance 1 & .095 & .200 & .704 & .134 & .118 \\
\hline Reliability 4 & .139 & .122 & .046 & .811 & .035 \\
\hline Reliability 2 & .140 & .182 & .127 & .805 & .092 \\
\hline Reliability 3 & .164 & .032 & .011 & \begin{tabular}{|c|}
784 \\
\end{tabular} & .189 \\
\hline Reliability 5 & .161 & .163 & .119 & 738 & .062 \\
\hline Responsiveness 2 & .118 & .090 & .096 & .080 & .821 \\
\hline Responsiveness 3 & .086 & .243 & .020 & .080 & \begin{tabular}{|l|}
751 \\
\end{tabular} \\
\hline Responsiveness 4 & .142 & .127 & .180 & .065 & .750 \\
\hline Responsiveness 1 & .270 & .276 & .009 & .195 & .695 \\
\hline Eigenvalue & 7.420 & 2.190 & 2.037 & 1.722 & 1.540 \\
\hline$\%$ of variance explained & 15.287 & 15.209 & 12.869 & 12.433 & 11.973 \\
\hline Alpha & .885 & .865 & .843 & .835 & .816 \\
\hline
\end{tabular}

Extraction method: Principal Component Analysis.

Rotation method: Varimax with Kaiser Normalization. Rotation converged in six iterations.

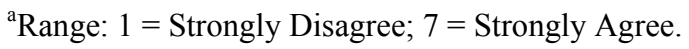

\subsection{Service quality and satisfaction}

A Pearson correlation analysis was carried out to determine the amount of association between the studied variables (Table 3 ). It was observed that all quality variables correlated in a positive and significance manner with satisfaction $(p<.001)$. The analysis indicated a high correlation between satisfaction and tangibility $(\mathrm{r}=.585)$, followed by reliability $(\mathrm{r}$ $=.526)$, empathy $(\mathrm{r}=.493)$, responsiveness $(\mathrm{r}=.484)$ and assurance $(\mathrm{r}=.364)$. The effect size of these correlations can be classified as medium to large based on Cohen's (1988) guidelines. 
Table 3. Means, Standard Deviations and Pearson Correlations of the Perceived Quality Dimensions and Satisfaction.

\begin{tabular}{|l|c|c|c|c|c|c|c|c|}
\hline & Mean & S.D. & 1 & 2 & 3 & 4 & 5 & 6 \\
\hline 1. Empathy & 4.029 & 1.148 & 1.00 & & & & & \\
2. Tangibility & 4.262 & 1.019 & .440 & 1.00 & & & & \\
3. Assurance & 3.668 & 1.114 & .395 & .343 & 1.00 & & & \\
4. Reliability & 4.244 & 1.029 & .414 & .348 & .234 & 1.00 & & \\
5. Responsiveness & 3.746 & 0.970 & .424 & .457 & .254 & .315 & 1.00 & \\
6. Satisfaction & 4.146 & 0.808 & .493 & .585 & .364 & .526 & .484 & 1.00 \\
\hline
\end{tabular}

Note: All correlations are significant at the 0.01 level (2-tailed).

To identify which service quality dimensions were correlated strongly with satisfaction, multiple regression analysis was conducted with the five subscales of service quality dimensions as predictor variables and satisfaction as the dependent variable. The satisfaction variable index was based on the arithmetic mean of six consecutive items on the scale, used for measuring general satisfaction towards municipal service. The mean value for the satisfaction variable was $x=4.146$, with a standard deviation of 0.808 . This means the respondents agreed that they were satisfied with the service (satisfaction was measured on a seven-point scale from 1 (very dissatisfied) to 7 (very satisfied). A Cronbach's alpha coefficient calculation of 0.871 showed the 6 -item instrument to be internally reliable.

Stepwise regression was used to examine the relative importance of the five service quality dimensions in determining satisfaction. A significance level of $5 \%$ was used. The model to be tested was:

$$
\mathrm{Y}=\mathrm{ax} 1+\mathrm{bx} 2+\mathrm{cx} 3+\mathrm{dx} 4+\mathrm{ex} 5+\mathrm{e}
$$

Where $\mathrm{Y}=$ Satisfaction; $\mathrm{x} 1=$ Tangibility; $\mathrm{x} 2=$ Reliability; $\mathrm{x} 3=$ Responsiveness; $\mathrm{x} 4=$ Assurance; $\mathrm{x} 5$ = Empathy; and e = Constant

To find the best regression model, an automated selection procedure of stepwise regression was applied. In the stepwise solution, the tests are performed at each step to determine the influence or contribution of each variable already in the equation as if it were entered last. So by doing this it makes it possible to select a set of independent variables that best predict the dependent variable, and thereby eliminate superfluous variables. The order of the inclusion of the independent variable is determined by the contribution of each variable, to explain the variance in the independent variable (Hair et al. 1998). In this case, the variable that explains the greatest amount of variance is entered first; the variable that explains the greatest amount of variance in conjunction with the first variable is entered second, and so on. The independent variables which do not meet the pre-established statistical criteria for inclusion in the equation are deleted at each successive step.

To test whether the assumptions of linearity, homoscedasticity and independence were met by 
the data, checks were undertaken by constructing the normal probability plot and residuals scatter plot. A visual inspection of the normal probability plot revealed that the residual plots were almost close to the normal straight diagonal line, suggesting that the residuals were approximate normal distribution. Additionally, the scatter plot (a plot of the studentized residuals versus the predicted values) revealed that most of the plots concentrated along the zero line in an almost rectangular shape, with relatively equal dispersion about zero and no strong tendency to be either greater or less than zero, verifying that the residuals were linear and homoscedastic. Thus there were no reasons to be concerned about the violation of regression assumptions.

To test for the possible presence of multicollinearity problem, a correlation matrix was run among the five independent variables. As shown in Table 3, the intercorrelations among the five independent variables were rather low, ranging from 0.234 to 0.457 . Thus, it was concluded that there were no reasons to be concerned as no high intercorrelations existed among these variables. However, the absence of high bivariate correlation does not imply lack of collinearity because the correlation matrix may not reveal collinear relationships involving more than two variables. Therefore, the tolerance values of the independent variables were assessed further while the regression analysis was run using the conventional tolerance value of 0.1 as the cut-off point for high multicollinearity (Hair et al. 1998). The analysis showed that all independent variables in the regression equation had high tolerance values ranging from 0.688 to 0.785 and the VIF values are all quite close to 1.0 (the highest was 1.454), indicating an absence of multicollinearity problem.

Table 4. Stepwise Regression Results of Service Quality with Satisfaction

\begin{tabular}{|c|l|c|c|c|c|c|c|}
\hline Model & Predictor & $\begin{array}{c}\text { B } \\
\text { coefficient }\end{array}$ & Beta $(\beta)$ & t-value & $p$-value & $\begin{array}{c}\text { F-ratio } \\
\text { for the } \\
\text { equation }\end{array}$ & $\begin{array}{c}\text { Adjusted } \\
R^{2}\end{array}$ \\
\hline \multirow{2}{*}{1} & (Constant) & 1.96 & & 9.913 & .000 & 128.189 & .353 \\
& Tangibility & .514 & .597 & 11.322 & .000 & & \\
\hline \multirow{2}{*}{3} & (Constant) & 1.38 & & 6.861 & .000 & 98.318 & .455 \\
& Tangibility & .359 & .417 & 7.540 & .000 & & \\
& Empathy & .291 & .369 & 6.667 & .000 & & .487 \\
& (Constant) & 1.13 & & 5.502 & .000 & 74.698 & \\
& Tangibility & .326 & .378 & 6.924 & .000 & & .50 \\
& Empathy & .229 & .290 & 5.056 & .000 & & \\
\hline \multirow{2}{*}{4} & Assurance & .176 & .211 & 3.911 & .000 & & \\
& (Constant) & 1.066 & & 5.224 & .000 & 59.323 & \\
& Tangibility & .285 & .331 & 5.835 & .000 & & \\
& Empathy & .210 & .267 & 4.66 & .000 & & \\
& Assurance & .146 & .175 & 3.20 & .002 & & \\
& Responsiveness & .106 & .150 & 2.679 & .008 & & \\
\hline
\end{tabular}

Note: None of the previously entered variables was removed in subsequent steps.

t-value of the estimate: /t-value/ $>1.64, \mathrm{p}>0.1$; /t-value/ $>1.96, \mathrm{p}>0.05$

Statistics on variables that entered the regression equation and that, collectively, explained 
portions of the variance in the dependent variable are summarized in Table 4. The overall $F$-test for the final regression model was highly significant $(F=59.323, p<.001)$, with four service quality dimensions entered the resulting equation: tangibility $(\beta=.331, p<.001)$, empathy $(\beta=.267, p<.001)$, assurance $(\beta=.175, p<.005)$, and responsiveness $(\beta=.15, p$ $<.05)$. The explanatory power of this model, as reported by the adjusted $R^{2}$ value was 0.5 , suggesting that 50 percent of the variability in the subjects' overall satisfaction was predicted by the service quality dimensions. According to Cohen (1988, p. 79-81), this effect size can be considered as large.

Stepwise ordering of service quality dimensions that entered the regression equation is as follows. Tangibility was the first variable that entered the equation as it was the most salient in explaining satisfaction. It alone contributes 35.3 percent of the variation. At Step 2, Empathy entered the regression equation and it improved the predictive efficiency of service quality (R-square) from 35.3 to 45.5 percent. Assurance, the next variable to enter the equation at Step 3, accounted for an additional 3.2 percent of the variation. Responsiveness was the final predictor that entered the equation and accounted for an additional 1.3 percent of the variation.

The relative importance of the service quality dimensions was indicated by their Standardized Beta Coefficients. As is evidence from Table 4, the strongest impact on satisfaction was by tangibility $(\beta=0.331)$. The next most important was empathy $(\beta=.267)$, followed by assurance $(\beta=.175)$ and responsiveness $(\beta=.15)$.

\section{Discussion}

The primary contribution of this work is to examine the quality of municipal services provided by local government in southern Thailand. For that purpose, we used 22-item SERVQUAL instrument to measure citizen perceptions of municipal service quality. The assessment of service quality investigated in this study has proved to perform reliably in the Thai setting. It is interesting to note that the five service quality dimensions found is almost entirely consistent with the dimensional structure outlined by Parasuraman et al. (1991). We believe that there may be some potentially universal facets of service quality and that perhaps we may not need to develop specific measures from scratch for each context. This would suggest that basing quality measurement efforts on SERVQUAL is appropriate for the assessing municipal services.

The study has also attempted to identify the most important service quality dimensions that determine citizen satisfaction with municipal council services. The results support the findings of previous research which indicates that service quality plays an important role in affecting customer satisfaction (Cronin, Brady \& Hult, 2000; Sivadas \& Baker-Prewitt, 2000; Lee, Lee \& Yoo, 2000; Olorunniwo, Hsu \& Udo, 2006). Four service quality dimensions namely were found to significantly predict citizen satisfaction, accounting for 50 percent of the variation. Tangibility emerged as the most important predictor or determinant of citizen satisfaction, followed by empathy, assurance, and responsiveness.

Our empirical findings provide several important managerial implications for municipal 
councils by offering them practical guidelines to improve quality attributes that would increase citizen satisfaction. From a strategic standpoint, municipal officials can determine the relative importance of the five service quality dimensions in predicting citizen satisfaction. By doing so, municipal officials can determine which service quality dimension(s) they should pay most attention to.

Given the importance of tangibility as a major determinant of satisfaction, as demonstrated in this study, it is imperative for municipal officials to identify the relevant extrinsic and intrinsic cues used by customers in order to effectively communicate to them the relevant quality signals. Municipal officials need to ensure that all tangible attributes related to employee performance create a desirable impact on customer perception of quality. This is important as customer continue to look for tangible cue as a means to reduce perceived risk and describe their service experience (Chen \& Chang, 2005).

In order to offer a consistently high standard of service delivery, municipal officials should make key performers aware of their role and provide them with adequate training. Empathy and listening skills are two central areas that need to be addressed in training those employees actually providing the service. Recognizing the dominant role played by the employees in delivering quality service, municipal officials should make sure that there are always sufficient staffing levels. In so doing, they will optimize service delivery and provide a prompt services at all times.

Finally, it is recommended that service quality be assessed on an annual basis. The initial assessment provides a baseline for comparison with future assessments. This comparison is essential for monitoring the effectiveness of service quality improvement efforts and identification of service quality trends as they emerge. The assessment would also provide a broader picture of interest to local governments who would then be aware of the potential areas of interest to their citizens (Scott \& Scieff, 1993). An annual assessment can help measure progress and would allow enough elapsed time between assessments for improvement efforts to have an impact, while at the same time still be frequent enough to identify emerging customer service trends (Dutka \& Frankel, 1993).

As with any empirical study, this study also had certain limitations that must be considered when assessing the outcomes of its findings and implications. The results pertain only to the respondents and generalizations to a wider population or service sector should be done with caution. Additional studies comparing service quality of citizens from different regions of Thailand or across different public service settings might produce interesting findings. Furthermore, the study could have been improved by conducting qualitative interviews with individual customers to ascertain other influences factors not identified in this analysis. Future work can also focus on developing a richer model that incorporates other potential variables beyond the two used in this study. 


\section{References}

Ahmed, S. M. Z. \& Shoeb, M. Z. H. (2009). Measuring service quality of a public university library in Bangladesh using SERVQUAL. Performance Measurement and Metrics, 10(1), 17-32.

Bejou, D., Ennew, C. T. \& Palmer, A. (1998). Trust, ethics and relationship satisfaction. International Journal of Bank Marketing, 15(3), 73-82.

Buttle, F. (1996). SERVQUAL: review, critique, research agenda. European Journal of Marketing, 30(1), 8-32.

Brady, M. K., Cronin, J. J. \& Brand, R. R. (2002). Performance-only measurement of service quality: a replication and extension. Journal of Business Research, 55(1), 17-31.

Brady, M. K. \& Robertson, C. J. (2001). Searching for a consensus on the antecedent role of service quality and satisfaction: An exploratory cross-national study. Journal of Business Research, 51(1), 53-60.

Brysland, A. \& Curry, A. (2001). Service improvements in public services using SERVQUAL. Managing Service Quality, 11(6), 389-401.

Chen, T. Y. \& Chang, H. S. (2005). Reducing consumers' perceived risk through banking service quality cues in Taiwan. Journal of Business and Psychology, 19(4), 521-540.

Cohen, J. (1988). Statistical Power Analysis for the Behavioral Sciences (2nd ed.). New York: Academic Press.

Cronin, J. J. \& Taylor, S. A. (1994). SERVPERF versus SERVQUAL: reconciling performance-based and perceptions-minus-expectations measurement of service quality. Journal of Marketing, 58, 125-131.

de Ruyter, K., Bloemer, J. \& Peeters, P. (1997). Merging service quality and service satisfaction. An empirical test of an integrative model. Journal of Economic Psychology, 18(4), 387-340.

Donnelly, M., Kerr, N. J., Rimmer, R. \& Shiu, E. M. (2006). Assessing the quality of police services using SERVQUAL. Policing: An International Journal of Police Strategies \& Management, 29(1), 92-105.

Donnelly M. \& Shiu, E. (1999). Assessing service quality and its link with value for money in a UK local authority's housing repairs service using the SERVQUAL approach. TQM Magazine, 10(4/5), 498-506.

Donnelly, M., Wisniewski, M., Dalrymple, J. F. \& Curry, A. C. (1995). Measuring service quality in local government: the SERVQUAL approach. International Journal of Public Sector Management, 8(7), 15-20.

Dutka, S. \& Frankel, L. (1993). Measurement errors in organizational surveys. The American Behavioral Scientist, 36, 472-81. 
Erevelles, S. \& Leavitt, C. (1992). A comparison of current models of consumer satisfaction/dissatisfaction. Journal of Satisfaction, Dissatisfaction and Complaining Behavior, 5, 104-114.

Fabrigar, L. R., Wegener, D. T., MacCallum, R. C. \& Strahan, E. J. (1999). Evaluating the use of exploratory factor analysis in psychological research. Psychological Methods, 4(3), 272-299.

Fisk, R. P., Brown, S. W. \& Jo, M. (1993). Tracking the evolution of the services marketing literature. Journal of Retailing, 69(1), 61-103.

Gaster, L. (1996). Quality services in local government: a bottom-up approach. Journal of Management Development, 15(2), 80-96.

Hair, J. F., Anderson, R., Tatham, R. \& Black, W. C. (1998). Multivariate Data Analysis (5th ed.). Upper Saddle River, NJ: Prentice Hall.

Kilbourne, W. E., Duffy, J. A., Duffy, M. \& Giarchi, G. (2004). The applicability of SERVQUAL in cross-national measurements of health-care quality. Journal of Services Marketing, 18(7), 524-533.

Krejcie, R. V. \& Morgan, D. W. (1970). Determining sample size for research activities. Educational and Psychological Measurement, 30(3), 607-610.

Lee, H., Lee, Y. \& Yoo, D. (2000). The determinants of perceived service quality and its relationship with satisfaction. Journal of Services Marketing, 14(3), 217-231.

Liong, C. Y., Mustafa, Z., Mohamed, W. N. \& Lee, P. W. (2007). Understanding customer needs of public bus services using SERVQUAL and Kano models. Journal of Quality Measurement and Analysis, 3(1), 33-45.

Nowacki, M. M. (2005). Evaluating a museum as a tourist product using the servqual method. Museum Management and Curatorship, 20(3), 235-250.

Othman, A. \& Ismail, W. R. (2008). Analytical hierarchy process for selection of banks with reference to service quality. Journal of Quality Measurement and Analysis, 4(1), 89-95.

Olorunniwo, F., Hsu, M. K. \& Udo, G. J. (2006). Service quality, customer satisfaction, and behavioral intentions in the service factory. Journal of Services Marketing, 20(1), 59-72.

Parasuraman, A., Zeithaml, V. \& Berry, L. (1985). A conceptual model of service quality and its implications for future research. Journal of Marketing, 49, 41-50.

Parasuraman, A., Zeithaml, V. \& Berry, L. (1988). SERVQUAL: a multiple item scale for measuring consumer perceptions of service quality. Journal of Retailing, 64(1), 12-40.

Parasuraman, A., Zeithaml, V. A. \& Berry, L. L. (1994). Reassessment of expectations as a comparison standard in measuring service quality: implications for further research. Journal of Marketing, 58, 111-124.

Ramsaran-Fowdar, R. R. (2007). Developing a service quality questionnaire for the hotel 
industry in Mauritius. Journal of Vacation Marketing, 13(1), 19-27.

Rodríguez, P. G., Burguete, J. L. V., Vaughan, R. \& Edwards, J. (2009). Quality dimensions in the public sector: municipal services and citizen's perception. Journal of International Review on Public and Nonprofit Marketing, 6(1), 75-90.

Sachdev, S. B. \& Verma, H. V. (2004). Relative importance of service quality dimensions: a multisectoral study. Journal of Services Research, 4(1), 93-116.

Scott, D. \& Shieff, D. (1993). Service quality components and group criteria in local government. International Journal of Service Industrial Management, 4(4), 42-53.

Sivadas, E. \& Baker-Prewitt, J. L. (2000). An examination of the relationship between service quality, customer satisfaction, and store loyalty. International Journal of Retail \& Distribution Management, 28(2), 73-82.

Sureshchandar, G. S., Rajendran, C. \& Kamalanabhan, T. J. (2001). Customer perceptions of service quality: A critique. Total Quality Management, 12(1), 111-124.

Tan, K. C. \& Kek, S. W. (2004). Service quality in higher education using an enhanced SERVQUAL approach. Quality in Higher Education, 10(1), 17-24.

Van Ryzin G. G. (2004). The measurement of overall citizen satisfaction. Public Performance and Management Review, 27(3), 9-28.

Wan Yusoff, W. Z., Ismail, M. \& Newell, G. (2008). FM-SERVQUAL: a new approach of service quality measurement framework in local authorities. Journal of Corporate Real Estate, 10(2), 130-144.

Wisniewski, M. (2001). Using SERVQUAL to assess customer satisfaction with public sector services. Managing Service Quality, 11(6), 380-388.

Wisniewski, M. (2001). Assessing customer satisfaction with local authority services using SERVQUAL. Total Quality Management \& Business Excellence, 12(7\&8), 995-1002.

Wisniewski, M. \& Donnelly, M. (1996). Measuring service quality in the public sector: the potential for SERVQUAL. Total Quality Management, 7(4), 357-365.

Zeithaml, V. A., Parasuraman, A. \& Berry, L. L. (1990). Delivering Quality Service. New York: The Free Press.

Zisis, P., Garefalakis, A. \& Sariannidis, N. (2009). The application of performance measurement in the service quality concept: the case of a Greek service organisation. Journal of Money, Investment and Banking, 9, 21-47. 